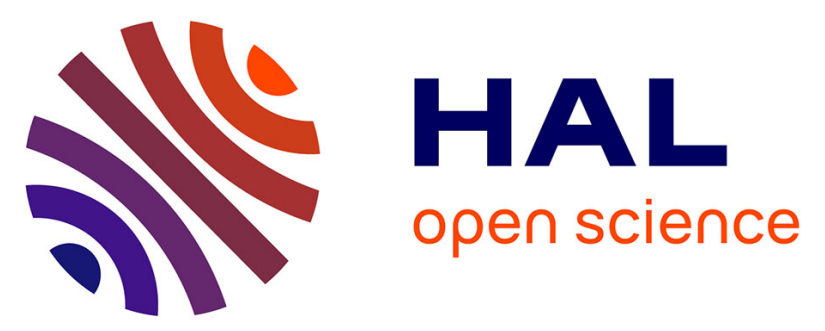

\title{
Self-Deformable Flexible Mems Tweezer Made of Poly (Vinylidene Fluoride)/Ionic Liquid Gel with Electrical Measurement Capability
}

Takafumi Yamaguchi, Naoto Usami, Kei Misumi, Atsushi Toyokura, Akio Higo, Shimpei Ono, Gilgueng Hwang, Guilhem Larrieu, Yoshiho Ikeuchi, Agnès Tixier-Mita, et al.

\section{To cite this version:}

Takafumi Yamaguchi, Naoto Usami, Kei Misumi, Atsushi Toyokura, Akio Higo, et al.. Self-Deformable Flexible Mems Tweezer Made of Poly (Vinylidene Fluoride) /Ionic Liquid Gel with Electrical Measurement Capability. 2021 21st International Conference on Solid-State Sensors, Actuators and Microsystems (Transducers), Jun 2021, Orlando (on line), United States. pp.18-21, 10.1109/Transducers50396.2021.9495482 . hal-03426266

\section{HAL Id: hal-03426266 https://hal.science/hal-03426266}

Submitted on 12 Nov 2021

HAL is a multi-disciplinary open access archive for the deposit and dissemination of scientific research documents, whether they are published or not. The documents may come from teaching and research institutions in France or abroad, or from public or private research centers.
L'archive ouverte pluridisciplinaire HAL, est destinée au dépôt et à la diffusion de documents scientifiques de niveau recherche, publiés ou non, émanant des établissements d'enseignement et de recherche français ou étrangers, des laboratoires publics ou privés. 


\title{
SELF-DEFORMABLE FLEXIBLE MEMS TWEEZER MADE OF POLY (VINYLIDENE FLUORIDE) /IONIC LIQUID GEL WITH ELECTRICAL MEASUREMENT CAPABILITY
}

\author{
${ }^{1}$ Takafumi Yamaguchi, ${ }^{1}$ Naoto Usami, ${ }^{1}$ Kei Misumi, ${ }^{1}$ Atsushi Toyokura, ${ }^{1}$ Akio Higo, \\ ${ }^{2}$ Shimpei Ono, ${ }^{3,4}$ Gilgueng Hwang, ${ }^{5}$ Guilhem Larrieu, ${ }^{1,3}$ Yoshiho Ikeuchi, ${ }^{1,3}$ Agnès Tixier-Mita, \\ ${ }^{6}$ Ken Saito, ${ }^{7}$ Timothée Lévi, and ${ }^{1,3}$ Yoshio Mita \\ ${ }^{1}$ The University of Tokyo (UTokyo), Tokyo, Japan, \\ ${ }^{2}$ Central Research Institute of Electric Power Industry, Kanagawa, Japan, ${ }^{3}$ Laboratory for \\ Integrated Micro Mechatronic Systems (LIMMS), National Center for Scientific Research (CNRS) - \\ UTokyo, Japan, ${ }^{4} \mathrm{C} 2 \mathrm{~N}-\mathrm{CNRS}$, Paris-Sacray, France, ${ }^{5}$ LAAS-CNRS, Toulouse, France, \\ ${ }^{6}$ Nihon University, Chiba, Japan, ${ }^{7}$ IMS-CNRS, Bordeaux, France,
}

\begin{abstract}
We demonstrated a self-bending flexible tweezer capable of simultaneous mechanical handling and electrical measurement. A soft cantilever of $2 \mathrm{~mm} \times 8 \mathrm{~mm}$ $\times 75 \mu \mathrm{m}$ bent by itself, and electrical signal observation through touched surface was successful. The working voltage $(1.5 \mathrm{~V})$ was the lowest, and normalized strain was one of the highest values as compared to world's similar devices, to our best knowledge. Unique fabrication process of flexible cantilever with novel ionic polymer-metal composites (IPMCs) was developed. The material was poly (vinylidene fluoride-co-trifluoroethylene) (PVDFTrFE) and ionic liquid (IL) by use of acetone solvent, and silver nanowire for electrodes. The IL of $50 \mathrm{wt} \%$ gave the largest $7 \mathrm{~mm}$ bending displacement at $+1.5 \mathrm{~V}_{\mathrm{DC}}$. The cantilever with the above actuator touched on a gold test surface, then electrical observation of alternating voltage of $700 \mathrm{mV}(1 \mathrm{kHz}$ and $4 \mathrm{kHz})$ was confirmed.
\end{abstract}

\section{KEYWORDS}

Self-deformable cantilever, flexible actuator, soft gripping, electrical observation, PVDF-TrFE, ionic liquid, silver nanowire

\section{INTRODUCTION}

To study living organisms, it is necessary to stimulate it and observe the response. So far, in some research a part of organism has been locally stimulated by chemical substances or observed electrically $[1,2]$. The devices in these studies had however some problems, such as tissue damage and lack of adhesion due to planar nature [1]. To solve these problems, we propose a flexible MEMS device. If we can realize a tweezer by a self-deformable cantilever (Fig. 1), the device will be able to observe a target sending electrical signal while gently gripping the target.

To realize such cantilever, we propose to employ an Ionic Polymer-Metal Composites (IPMCs) actuator. IPMCs actuators attract attentions with their flexibility, large strain, good conductivity and low operation voltage [3]. An IPMC is composed of polymer and mobile ions with electrodes. When voltage is applied, cations and anions move to opposite direction [3]. The actuator bends to either side of electrodes because of the size difference of the mobile anions and cations. As the polymer, Nafion has commonly been used up to present [3]. However, recent studies have often applied poly (vinylidene fluoride) (PVDF) $[4,5]$ and

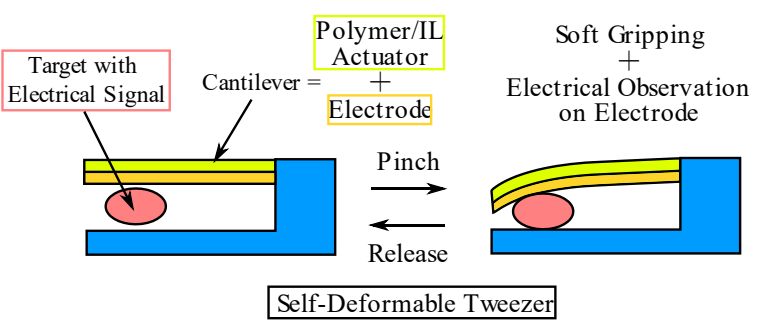

Figure 1. Self-deformable tweezer enables mechanical gripping and electrical observation simultaneously.

its co-polymer $[6,7,8,9]$ to IPMCs. PVDF is known as a ferroelectrics and piezoelectric material that has as low Young's modulus ( $\sim 500 \mathrm{MPa})$ as that of Nafion [8]. PVDF in IPMCs is occasionally used as co-polymer structure such as poly (vinylidene fluoride-co-hexafluropropylen) (PVDF-HFP [6, 7, 8]), poly (vinylidene fluoride-cotrifluoroethylene) (PVDF-TrFE [8]), and poly (vinylidene fluoride-co-chlorotrifluoroeth-ylene) (PVDF-CTFE [8, 9]) with ionic liquid (IL) as fluid ions. IL is salt that exists as fluid stably at wide ranged temperature, having low vapor pressure, incombustibility and good conductivity [4]. Above these PVDF co-polymers with IL, the maximum displacement was $3.5 \mathrm{~mm}$ of for a $10 \mathrm{~mm}$ length actuator at $100 \mathrm{mHz} 5.0 \mathrm{~V}_{\mathrm{pp}}$ made of PVDF-TrFE including 1ethyl-3-methylimidazolium bis (trifluoromethanesulfonyl) imide (EMIMTFSI) as IL with gold sputtered electrode [8].

As discussed above, IPMCs actuator composed of PVDF co-polymers exhibit big movements at low voltage and is suitable for the MEMS soft tweezer handling delicate materials, such as organic tissues. Though a lot of research has investigated a variety of actuator with electrode [4-8], little has applied such actuators to some practical application [3]. Based on above consideration, we fabricated PVDF-TrFE/EMIMTFSI composites actuator with silver nano wire electrodes for MEMS tweezer (Fig. 1). The silver nanowire of the electrodes is an assembly of silver wires that are nm scales, expecting higher flexibility and conductivity than silver, gold and platinum in sheet form electrodes. The combination of IPMCs of these polymer, IL, electrodes, and solvent is unique in the world, to our best knowledge. The fabrication process of this PVDF-TrFE/IL composites was established by use of the acetone solvent, with the silver nanowire coated as the electrodes. The mechanical characteristics of the actuator with such electrodes was verified whether it had the appropriate performance to be adopted to the Fig. 1 
tweezer. Finally, a tweezer with a cantilever of the actuator was confirmed to observe the electrical signal that is sinusoidal wave voltage, on a gold target electrode.

\section{FABRICATION OF IPMCS TWEEZER}

\section{Materials}

Ionic liquid was EMIMTFSI manufactured by TCI, Tokyo Chemical Industry (Japan,) whose purity is $98.0 \%$. It was stored and used in glove box under nitrogen atmosphere in order not to absorb moisture or carbon dioxide. It was heated up to $110^{\circ} \mathrm{C}$ in 5 minutes on hotplate to evaporate moisture when used. As a polymer, we used PVDF-TrFE, PIEZOTECH ${ }^{\circledR}$ FC25 produced from Arkema Piezotech (France.) It contains $25 \mathrm{~mol} \%$ trifleoroethylene (TrFE.) The solvent was acetone (99.5\% purity,) obtained from Kanto Chemical Holdings (Japan.) All the above substances were stored at $25^{\circ} \mathrm{C}$, atmospheric pressure. The electrode was silver nanowire that was made in Merck (Germany.) The concentration was $5 \mathrm{mg} / \mathrm{mL}$ in water. It was kept at about 2 to $6^{\circ} \mathrm{C}$, under atmospheric pressure.

\section{Fabrication process of PVDF-TrFE/Ionic liquid membranes}

First, we fabricated three types EMIMTFSI/PVDFTrFE composites, in which mass proportion of EMIMTFSI was $30,50,70 \mathrm{wt} \%$. From now on, this polymer/IL composites are called as "ionic gel actuator." The weight of PVDF-TrFE was either $150 \mathrm{mg}$ or $300 \mathrm{mg}$, hence 6 actuators membranes were made in total. These actuators were named as 30a, 30b, 50a, 50b, 70a, 70b. '30' and ' 50 ' refers to weight proportion of EMIMTFSI, and ' $a$ ' and ' $b$ ' refer to $150 \mathrm{mg}$ and $300 \mathrm{mg}$ of PVDF-TrFE, respectively.

The process flow was as follows. Appropriate amount of PVDF-TrFE was put in glass bottle and acetone was added to dissolve solute to $5 \mathrm{wt} \%$. The solution was stirred on $50^{\circ} \mathrm{C}$ hotplate for more than 24 hours. EMIMTFSI was added and dissolved in the previous solution. This liquid was also stirred at $25^{\circ} \mathrm{C}$ (room temperature) for more than 24 hours. After the agitation, the solution was spread into a Petri dish of size $\varphi 80 \times 17 \mathrm{~mm}$ and dried covered with a lid at $25^{\circ} \mathrm{C}$ for more than 24 hours to form film by evaporating acetone. All the process was conducted in the glove box.

As a result, among six membranes, four $(30 \mathrm{~b}, 50 \mathrm{a}, 50 \mathrm{~b}$, $70 \mathrm{~b})$ was obtained and two (30a, 70a) was broken because the two membranes were too thin to be peeled off from the Petri dish. The next process of coating electrodes was applied to these four membranes.

\section{Coating of silver nanowire electrodes}

The membranes were cut about $20 \times 20 \mathrm{~mm}$ squares before coating. They were put in a Petri dish and coated with silver nano wire of water solvent by a syringe. In order to evaporate solvent completely, the dish was heated on hot plate at $110^{\circ} \mathrm{C}$ for 8 minutes. The membrane was cooled down for 5 minutes at $25^{\circ} \mathrm{C}$ (room temperature.) This process was done to the other side of the membrane. The film was peeled off and cut into $2 \times 10 \mathrm{~mm}$ square by UV laser cutter (LPKF ProtoLaser U4).

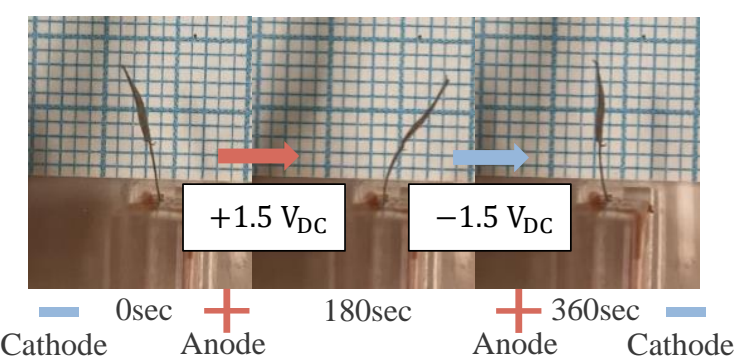

(a)

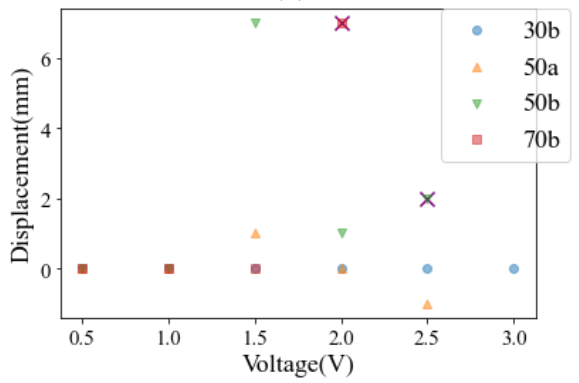

(b)

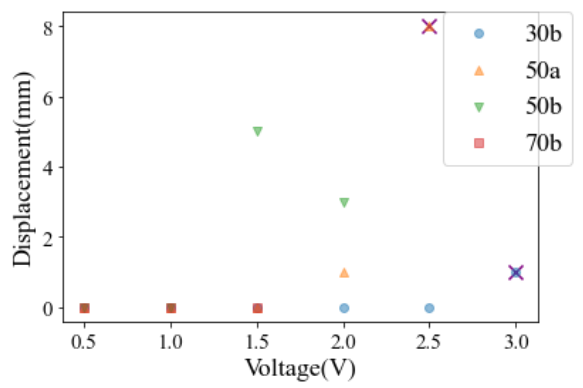

(c)

Figure 2. Measurement of mechanical features. (a): Bidirectional bending motion of $50 \mathrm{~b}$ at $\pm 1.5 \mathrm{~V} \mathrm{DC}$. $(b, c)$ : Displacements of four actuators at 0.5 to $3.0 V_{\mathrm{DC}}$, (b) At positive voltage, (c) at negative voltage.

Thickness of obtained membranes with or without electrodes were observed by laser microscope OLYMPUS LEXT OLS5000. Thickness of the membranes 30b, 50a, $50 \mathrm{~b}, 70 \mathrm{~b}$ after electrodes coated was 52.6, 65.6, 75.3, $87.7 \mu \mathrm{m}$, respectively. This result shows that the more IL weight ratio was, the thicker the membranes were. The ionic gel contained IL and swelled as the weight ratio of IL. The thickness of electrodes layers was measured to vary from 0.2 to $11.2 \mu \mathrm{m}$.

\section{RESULTS AND DISCUSSIONS}

\section{Mechanical Characteristics of Ionic Gel Actuator}

The $2 \times 2 \mathrm{~mm}$ part of the $2 \times 10 \mathrm{~mm}$ IPMC actuator was fixed between copper tape electrodes. With DC supply Hewlett Packard E3640A, the DC voltage was applied for 3 minutes, and more 3 minutes in the opposite direction, from $0.5 \mathrm{~V}$ to $3.0 \mathrm{~V}$ in $0.5 \mathrm{~V}$ increments. The displacement was read in $1 \mathrm{~mm}$ unit using a graph sheet.

As shown in Fig. 2 (a), the actuator always bended to the anode side (positively charged electrode) because the cation was bigger than the anion in EMIMTFSI. Fig. 2 (b) and (c) are displacements obtained in 3 minutes after the voltage was applied, in the forward (b) or reverse (c) 
Table 1: Performance Comparison

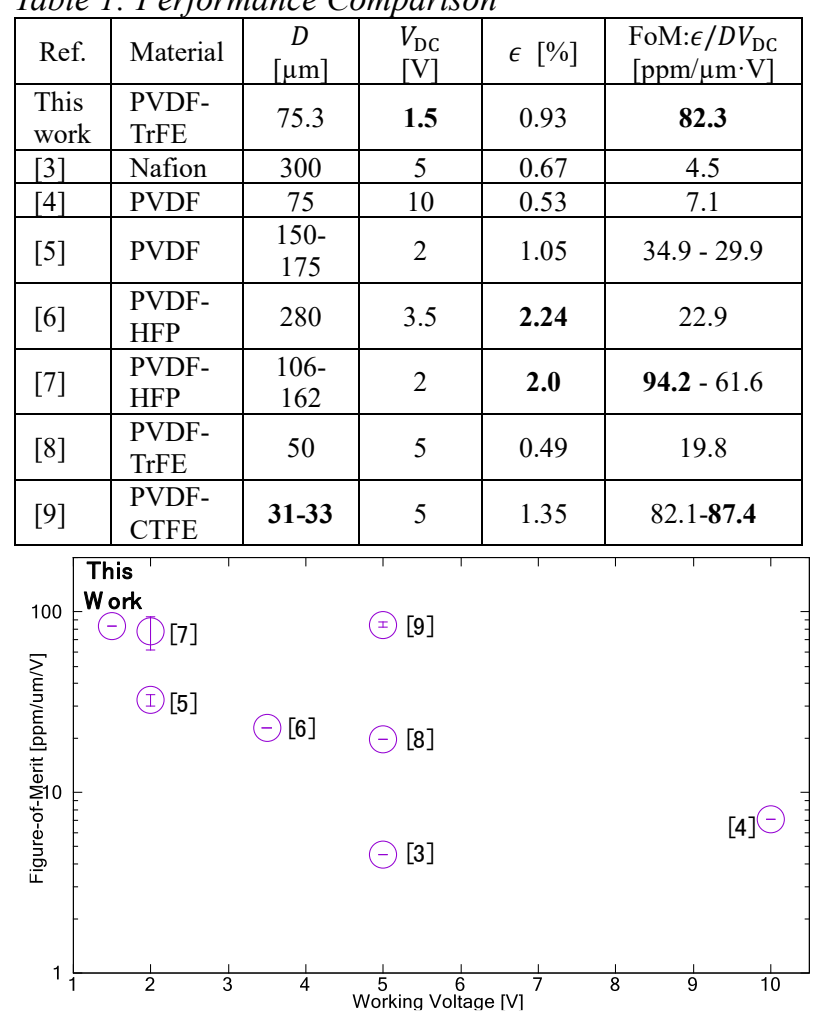

Figure 3: Figure-of-Merit and Working Voltage

directions, respectively. Four cantilevers made at certain conditions became conductor during measurement, supposedly, the electrical double layer is destroyed. The current rapidly increased and aborted at $3 \mathrm{~A}$, limit current of the used DC supply. Such case is also plotted with cross marks on the Figs. 2 (b) and (c), 50a and 50b had significant displacement, though $30 \mathrm{~b}$ and $70 \mathrm{~b}$ did not.

\section{State-of-the-art Performance Comparison}

The largest bending was obtained by of $50 \mathrm{~b}$ actuator at $1.5 \mathrm{~V}_{\mathrm{DC}}$. The values were $7 \mathrm{~mm}$ in the forward direction and $5 \mathrm{~mm}$ in reverse direction. This maximum displacement of $7 \mathrm{~mm}$ at $1.5 \mathrm{~V}$ was compared with the ones of previous research works that employ Nafion [3] and PVDF composites [4-9]. The following equation (1) was used to evaluate the mechanical performance of actuators:

$$
\epsilon=\frac{2 D \delta}{L^{2}+\delta^{2}}\left(=\frac{D}{R}\right),
$$

where $\epsilon, D, \delta, L, R$ is normalized strain, thickness, displacement, free length of actuator, and curvature radius, respectively. Because $\epsilon$ is in proportion to $D$ and $\delta$ $(\delta>\sqrt{L})$ and supposed to follow applied voltage $V_{\mathrm{DC}}$, we can define figure-of-merit (FoM) as $\epsilon / D V_{\mathrm{DC}}$. The values are summarized in Fig. 3. By comparing FoM plotted in Fig. 3, we can conclude that our developed actuator realized the lowest working voltage $V_{\mathrm{DC}}$ and high FoM comparable to the state-of-the arts [7] [9].

\section{Demonstration of Tweezer as Electrical Probe}

We have made a demonstration of our self-deformable cantilever actuator as an electrical probe. The cantilever was held by a jig composed of printed circuit. The jig had

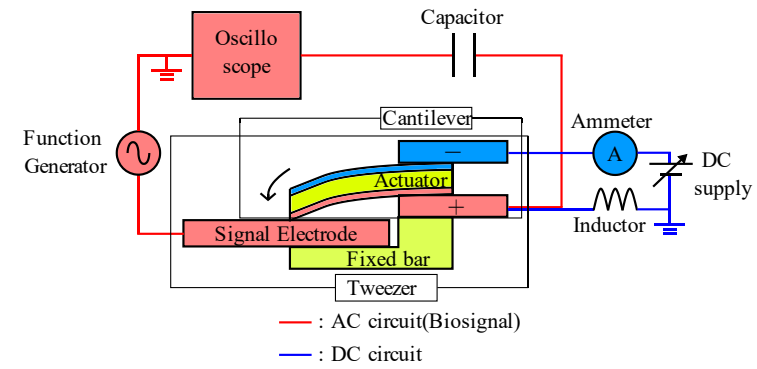

Figure 4. Schematic of the tweezer circuit

Table 2. $v_{A C}$ observed at $1 \mathrm{kHz}$ and $4 \mathrm{kHz}$.

\begin{tabular}{|c|c|c|}
\hline Frequency & Contact voltage & Released voltage \\
\hline $1 \mathrm{kHz}$ & $43 \mathrm{mV}$ & $105 \mathrm{mV}$ \\
\hline $4 \mathrm{kHz}$ & $36 \mathrm{mV}$ & $60 \mathrm{mV}$ \\
\hline
\end{tabular}

two electrodes, one fixed bar, a gold signal electrode. In Fig. 4, blue circuit was direct current $\left(V_{\mathrm{DC}}\right)$ for cantilever operation, and red circuit was alternating current $\left(v_{\mathrm{AC}}\right)$ mimicking a biosignal. They were electrically separated by using capacitor and inductor (known as Bias-T). When $V_{\text {DC }}$ was applied, the cantilever moved to and touched the gold signal electrode. After the red circuit was closed by actuation of IPMCs cantilever, the AC signal could be observed at function generator.

The cantilever repeated contact and release to the signal electrode for 5 times in a row. In Fig. 4, the function generator, ammeter, DC supply was respectively RIGOL DG4202, the ammeter mode of HIOKI DT4253, 1.5V alkaline battery. The $v_{\mathrm{AC}}$ was $700 \mathrm{mV}$ of 1 or $4 \mathrm{kHz}$. The $10 \mathrm{pF}$ ceramic capacitor and $47 \mathrm{mH}$ lead inductor were used. The oscilloscope GW instek GDS-2072A was used as Math mode, which could pick up the wave of target frequency in the observed voltage wave by Fast Fourier Transformation. The $v_{\mathrm{AC}}$ in contact and release, movement of the actuator and the transition of current was recorded by video camera SONY HDR-PJ680.

As shown in Table 2, in both 1 and $4 \mathrm{kHz}$ frequency the voltage when the actuator touched the signal electrodes was more than 1.5 times as large as when the actuator was open. Therefore, the PVDF-TrFE/EMIMTFSI gel composites actuator with silver nanowire electrodes was able to observe the sine wave voltage imitating biosignal. Figs. 5 (a), (b), (c) show the movement, $v_{\mathrm{AC}}$ of the actuator and current. When the actuator touched the signal electrodes like middle of Fig. 5 (a), $v_{\mathrm{AC}}$ increased abruptly at a purple point Fig. 5 (b). After 40 seconds of voltage application, the DC current stayed constant at $3 \mu \mathrm{A}$ (Fig. 5 (c)). The $v_{\mathrm{AC}}$ stayed around $100 \mathrm{mV}$, when the actuator and the signal electrode are thoroughly conducted.

\section{Estimation of Equivalent Circuit of Tweezer}

Based on the measurement we have estimated an equivalent circuit as shown in Fig. 6. A DC circuit of the actuator of bending operation is drawn with blue lines. The input resistance of ammeter is $1 \mathrm{M} \Omega . R_{1}$ is a resistor which represents the leak current of the actuator, $R_{2}$ is triggered by ionic conduction of IL movement, and $C_{1}$ is electric double layer capacitor of IPMCs. These 


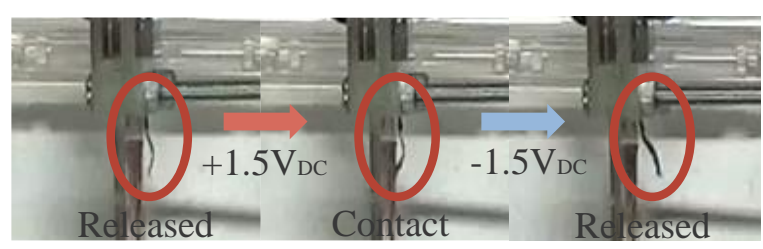

(a)

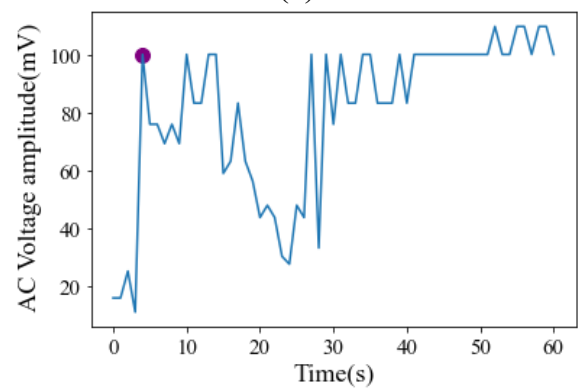

(b)

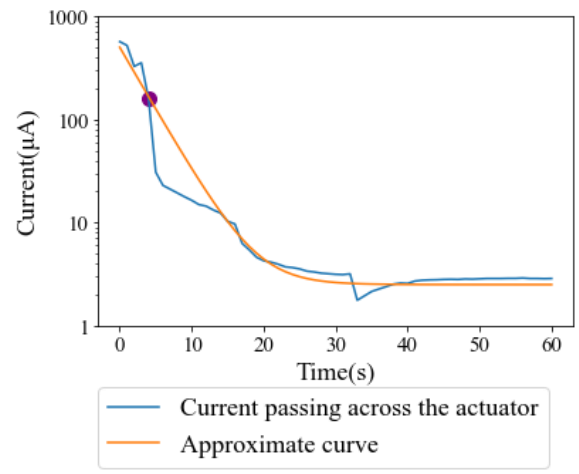

(c)

Figure 5. Characteristics of the tweezer. (a): movement of tweezer, $(b): v_{A C}$ observed, at third time operation. (c): current when $+1.5 V_{D C}$ was applied.

parameters were determined with the current of Fig. 5 (c), the inductance ignored because the buffering current of capacitance was much larger than that of inductance. By estimation from the data, $R_{1}=6 \mathrm{M} \Omega, R_{2}=2 \mathrm{k} \Omega$ and $C_{1}=1.2 \mathrm{mF}$, from approximate curve in Fig. 5 (c). The PVDF-TrFE/EMIMTFSI membrane has a huge insulation resistance to DC and some ionic conductive resistance to AC. Moreover, it was shown that ionic gel actuator has very large capacitance, generally called "supercapacitor."

The equivalent circuit for AC signal was a red circuit in Fig. 6. $R_{\mathrm{c}}$ is a series resistance, in which a resistance between copper electrodes of the jig and silver nanowire electrodes of the actuator, and a resistance of the silver nanowire electrodes. $R_{\mathrm{p}}$ and $C_{\mathrm{p}}$ are each contact resistance and capacitance between signal gold electrodes and actuator electrodes. When the actuator was open $\mathrm{R}_{\mathrm{P}}$ was infinite. The estimated values from table were $\left(R_{\mathrm{c}}, R_{\mathrm{p}}, C_{\mathrm{p}}\right)=(500 \mathrm{k} \Omega, 1 \mathrm{k} \Omega, 1$ to $100 \mathrm{pF})$. This result explains that $R_{\mathrm{c}}$ was the dominant factor for the signal decay from $700 \mathrm{mV}$ to $100 \mathrm{mV}$.

\section{CONCLUSIONS}

Towards biological MEMS devices that manipulate and observe biological tissues, we could fabricate new PVDF-TrFE /EMIMTFSI composites gel actuators with the silver nanowire electrodes by the acetone solvent.

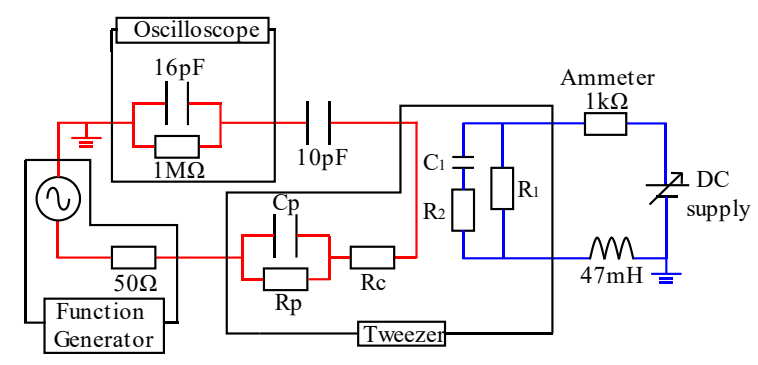

Figure 6. DC (blue) and $A C$ (red) equivalent circuits

The actuator of 50wt $\%$ EMIMTFSI had the largest $7 \mathrm{~mm}$ bending at $1.5 \mathrm{~V}_{\mathrm{DC}}$. The actuator was applied to the cantilever of the tweezer, which could observe $700 \mathrm{mV}, 1$ or $4 \mathrm{kHz}$ sine wave signal, first in the world. The circuit elements of the tweezer were also estimated, which indicated that this actuator had huge capacitance and unexpected large resistance of electrodes. The authors will examine remaining issues for demonstration with cells with better $\mathrm{S} / \mathrm{N}$ ratio: actuator reliability improvement, resistivity decrease of nanowire electrode, dedicated signal wiring introduction.

\section{ACKNOWLEDGEMENTS}

This work was partially supported by CREST, JST JPMJCR20T2 and the Internal Project of Laboratory for Integrated MicroMechatronic Systems (LIMMS, CNRSUTokyo IIS, UMI 2820.) The fabrication was carried out in MEXT Nanotechnology Platform at the Takeda Sentanchi Super clean room.

\section{REFERENCES}

[1] Tang, Yujie Tanye, et al., Lab on a Chip, 11(13), 2247-2254, 2011.

[2] Jonsson, Amanda, et al., 113(34), 9440-9445, 2016.

[3] He, Qingsong, et al., Smart Materials and Structures, 29(4), 045013, 2020.

[4] Mejri, R., et al., Journal of Non-Crystalline Solids, 453, 8-15, 2016.

[5] Terasawa, N, et al., Sensors and Actuators B: Chemical, 160(1), 161-167, 2011.

[6] Fukushima, T, et al., Angewandte Chemie International Edition, 44(16), 2410-2413, 2005.

[7] Sugino, T, et al., Sensors and Actuators B: Chemical, 141(1), 179-186, 2009.

[8] Dias, Juliana C; et al, Electrochimica Acta, 296, 598-607, 2019

[9] Liu, Yang, et al., Macromolecules, 45(12), 5128-5133, 2012.

[10] Yan, Yunsong, et al., Advanced Materials, 29(23), 1606109, 2017.

\section{CONTACT}

T. Yamaguchi and Y.Mita, Tel: +81-3-5841-6023;

E-Mail: mems@if.t.u-tokyo.ac.jp 